ESTRATÉGIA 


\title{
A INFLUENCIA DA ESTRATÉGIA DE PATROCÍNIO NO DESEMPENHO
}

\author{
THE INFLUENCE OF STRATEGY OF SPONSORSHIP ON PERFORMANCE
}

Jessica Nunes de Alcântara

Universidade Federal de Lavras

Sabrina Soares da Silva

Universidade Federal de Lavras

Francisval de Melo Carvalho

Universidade Federal de Lavras
Data de submissão: 25 jan. 20 | 8. Data de aprovação:

02 jun. 20 | 8. Sistema de avaliação: Double blind review.

Universidade FUMEC / FACE. Prof. Dr. Henrique Cordeiro

Martins. Prof. Dr. Cid Gonçalves Filho.

\section{RESUMO}

Neste trabalho verificou a influência da estratégia de patrocínio às indústrias esportiva e criativa sobre o desempenho das empresas brasileiras de capital aberto no período de 2007 a 2013. A amostra foi constituída de 31 empresas que tem suas ações negociadas na Brasil, Bolsa, Balcão (B3) e que possuem balanços sociais lbase. A natureza do estudo é quantitativa e os dados foram coletados por meio do banco de dados Economática $\AA$, balanços sociais lbase, relatórios administrativos, relatórios sociais e de sustentabilidade publicados anualmente pelas empresas estudadas. A técnica estatística utilizada para atender o objetivo proposto foi a regressão múltipla. Como resultado, percebeu que o patrocínio ao esporte, bem como o patrocínio à cultura, tem relação positiva com o desempenho econômico das empresas. Os resultados deste trabalho são relevantes, pois mostram a importância econômica para as empresas que adotam patrocínios as indústrias esportiva e criativa como estratégia.

\section{PALAVRAS-CHAVE}

Estratégia de patrocínio. Desempenho. Indústria Criativa. Indústria Esportiva. 


\section{ABSTRACT}

This study verified the influence of the sport and creative industries sponsorship strategy on the performance of Brazilian public companies from 2007 to 2013.The sample consisted of 31 companies that have shares traded on the Brasil, Bolsa, Balcão (B3) and have social reports IBASE.The nature of the study is quantitative and data were collected through the Economática ${ }^{\circledR}$ database, IBASE social reports, administrative reports, social and sustainability reports published annually by the companies studied.The statistical technique used to meet the proposed objective was multiple regression. As a result, it was concluded that, the sponsorship to the sport as well as the sponsorship of culture, has positive relationship with economic performance of companies. These results show the economic importance for companies that adopt the sponsorship of the sport industry and the creative industry as a strategy.

\section{KEYWORDS}

Sponsorship strategy. Performance. Sports industry. Creative industry.

\section{INTRODUÇÃO}

O governo brasileiro tem criado incentivos fiscais, desde a década de 1990, visando atrair investimentos para áreas de cultura e esporte. Essa prática é antiga, e vem sendo adotada por muitos outros governos, o que legitimou duas industrias: criativa, relacionada a bens culturais; e, esportiva relacionada a bens esportivos. Em contrapartida, as empresas viram a oportunidade de investir em cultura e esportes, por meio de patrocínios, podendo aumentar o desempenho através da difusão, valorização e construção de uma marca socialmente responsável.

A estratégia adotada pelas empresas tem sido de extrema importância na busca pelo aumento da rentabilidade das mesmas (KUPFER; HASENCLEVER, 2002), uma vez que esta estratégia atrai investimentos para a empresa, aumentando o seu valor de mercado. Consequentemente, as empresas melhoram o seu desempenho econômico, por meio da criação de valor sobre a marca. Kayo et al (2008) afirma que as estratégias definidas pela empresa afetam positivamente ou negativamente na valorização da marca.

$\mathrm{Na}$ estratégia de patrocínio, enquanto a empresa patrocinada visa ao suporte, seja financeiro ou prestação de serviços, a empresa patrocinadora visa à difusão e reconhecimento da marca (REIS; SANTOS, 1996). O patrocínio leva a associação das marcas, patrocinadas e patrocinadoras. $O$ patrocínio, então passou a ser visto como uma plataforma versátil para a comunicação com vários grupos de interesse, ampliando o objetivo das partes interessadas, no que se refere à medição de desempenho, que vai além do retorno sobre o investimento no patrocínio em si (MEENAGHAN, 20 I3).

O Patrocínio no Brasil, ganhou popularidade nos últimos anos, já que as empresas podem destinar $1 \%$ e $4 \%$ do seu imposto de renda devido para financiar esporte e 
cultura, respectivamente. Isto se tornou o principal incentivo para a prática dessa estratégia, uma vez que há grande exposição da marca patrocinadora, tornando a publicidade indireta, certa, e de baixo custo (REIS; SANTOS, 1996) e ainda, valorizando como uma empresa sócio responsável.

Mesmo com os incentivos oferecidos pelo governo, poucas são as empresas de capital aberto que têm utilizado desse benefício fiscal. Portanto, diante do exposto, pergunta-se:A estratégia de patrocínio meIhora o desempenho econômico das empresas patrocinadoras?

Assim, esse trabalho tem o objetivo de mensurar, do ponto de vista econômico e financeiro, a influência das ações estratégicas de patrocínio, às indústrias esportiva e criativa, das empresas brasileiras de capital aberto, no período entre 2007 a 2013. Por meio de uma regressão múltipla com dados em painel, esse trabalho busca contribuir para as discussões relacionadas ao desempenho econômico das empresas brasileiras de capital aberto patrocinadoras, evidenciando a influência da estratégia de patrocínio à indústria esportiva bem como a influência da estratégia de patrocínio à indústria criativa sobre o desempenho de empresas patrocinadoras.

\section{REVISÃO BIBLIOGRÁFICA Desempenho Econômico}

Perez e Famá (2006) afirmam que o desempenho econômico consiste basicamente na capacidade da firma em gerar lucro a partir dos capitais investidos, através da criação de valor para a empresa. Nessa perspectiva, Hoji (2006) destaca dois conceitos para se medir o valor adicionado aos proprietários. $O$ primeiro, segundo Young e O'Byrne (2003), o Economic Value Added
(EVA) mede a diferença, em termos monetários, entre o retorno sobre o capital de uma empresa e o custo desse capital. $O$ segundo, Market Value Added (MVA), consiste na apuração do valor presente líquido do fluxo de caixa futuro (HOJl, 2006).

Porém, os teóricos da Organização Industrial (Ol) destacam que o desempenho de uma empresa sofre influências de três fatores seminais: a estrutura da indústria, as características da empresa e a adoção de estratégias apropriadas por elas. A partir dessa afirmação, se elaborou o modelo teórico Estrutura-Conduta-Desempenho.

O modelo Estrutura-Conduta-Desempenho, ECD, um dos pilares da Economia Industrial, têm como objetivo a análise da alocação dos recursos escassos sob as hipóteses de equilíbrio e maximização dos lucros. Completando, Scherer e Ross (1990) afirmam que o objetivo deste modelo é estudar as variáveis que influenciam no desempenho econômico, permitindo, assim, a elaboração de teorias que detalhem a ligação existente entre essas variáveis e o desempenho da empresa.

Segundo Holanda Filho (1983), pesquisas que utilizam este modelo objetivam relacionar variáveis que mensurem aspectos da estrutura de mercado (concentração, diferenciação, barreiras à entrada) com o comportamento das empresas, ou seja, a conduta da mesma (política de preços, pesquisas e inovações, propaganda), e a conduta com variáveis do desempenho (eficiência na adoção de novas técnicas, progresso econômico, entre outros). Carneiro (2007) afirma que diferentes posturas estratégicas conduzem a diferentes desempenhos em determinadas circunstâncias.

Em resumo, os autores do modelo teórico ECD acreditavam que a estrutura da 
indústria na qual empresa está inserida, leva a empresa a adotar um tipo de determinada postura, conduta, enfim estratégia. Essa estratégia adotada pela empresa afetará o desempenho da mesma. Porém, esse modelo apresentava alguns vieses, sendo um dos principais, a falta de importância atribuída às condutas das empresas no processo de concorrência, para a não aceitação da existência de causalidade menos rígida e impossibilidade de uma relação interativa entre as variáveis de ECD.Atualmente, com o desenvolvimento de novos trabalhos, admite-se que além de variáveis da estrutura, outras podem ser relevantes para estudar o desempenho econômico da empresa.

Nesse sentido, os teóricos passaram a considerar, nas últimas décadas que as características específicas de cada empresa também influenciam no seu desempenho. Assim, na teoria da firma, a Visão Baseada em Recursos (Resource Based View - RBV) voltou os estudos para dentro das empresas, atribuindo a responsabilidade do desempenho na firma nas características específicas da mesma, como tamanho e experiência destacada por Penrose (2006). Ou seja, a RBV é ancorada na análise dos recursos e capacidades controladas pela firma, sendo aqueles atributos que capacitam a firma na definição e implantação de estratégias. Esse termo RBV foi instituído para tratar os meios de se alcançar a vantagem competitiva através da perspectiva dos recursos (WERNERFELT, 1984).Assim, autores como Barnard (1938), Penrose (2006) e Selznick (1957) afirmam que os recursos internos da organização, ou seja, as diferenças individuais entre as firmas são a base fundamental para o desenvolvimento de estratégias. Brito e Vasconcelos (2005) argumentam também que o sucesso duradouro da empresa é em função de recursos competitivos únicos da firma.

A RBV afirma que os recursos podem ser variáveis de acordo com o ramo em que as empresas atuam, ou seja, elas são heterogêneas em termos de recursos e capacidades.Além disso, essas especificidades só podem ser mantidas se existirem importantes barreiras à entrada do mercado. A compreensão da heterogeneidade advém do pressuposto de que a natureza da competição é determinada pelo estabelecimento de barreiras à imitação e a inovações. A forma como as firmas utilizam seus recursos internos faz com que elas sejam basicamente heterogêneas (CRUBELLATE; PASCUCCI; GRAVE, 2008; PETERAF, I993; RUGMAN;VERBEKE, 2002).

Assim, essas duas teorias combinadas buscam explicar os diferentes desempenhos das empresas que estão inseridas em uma mesma indústria. Por outro lado, as empresas têm que buscar melhorar seu desempenho, priorizando seu diferencial competitivo, aumentando o valor agregado de bens intangíveis por meio do posicionamento de suas marcas, utilizando estratégias como o patrocínio.

\section{Patrocínio}

O objetivo básico de elaboração de uma estratégia de marketing é influenciar na formação das preferências dos consumidores, aumentando a demanda por certo produto ou serviço, o que, consequentemente, busca causar uma variação na rentabilidade das empresas. Perante isso, o marketing não é apenas considerado fundamental no processo de diferenciação, mas 
também é essencial na estratégia competitiva das empresas.

A diferenciação é um fator que pode gerar barreiras à entrada no mercado, pois as empresas que são entrantes têm de realizar altos gastos em propaganda e esforços substanciais para tentar reverter um pouco a predileção dos consumidores por determinadas marcas já estabelecidas, já que a marca é um aspecto de diferenciação assumido por consumidores (KUPFER; HANSENCLEVER, 2002). Segundo os mesmos autores, 0 poder de influência dos meios de comunicação de massa nas preferências dos consumidores leva as empresas a alocarem um grande volume de recursos em propaganda, que se tornou uma atividade econômica importante na economia industrial. Assim, o patrocínio se tornou popular por fazer a propagação das marcas empresariais de maneira indireta, ou seja, sem que os consumidores percebam a propaganda diretamente, transformando-se em uma importante ferramenta de competição para as empresas que patrocinam.

O patrocínio, segundo Reis e Santos (1996), é considerado uma atividade comercial na qual a empresa patrocinadora oferece suporte, geralmente financeiro, em troca de direitos e/ou associações. Essa autora caracteriza o patrocínio como uma relação de troca do tipo prestação/ contraprestação. Essa estratégia eleva a percepção da marca e reflete diretamente na imagem da marca da empresa patrocinadora, não somente pela associação com a empresa patrocinada, como também por criar uma imagem de que a empresa é socialmente responsável.

Para ocorrer as atividades de patrocínio, existem várias alternativas, podendo ser individuais ou em grupo, a celebridades atletas, times e eventos, como os esportivos, culturais, musicais, científicos ou sociais. O patrocinador, para localizar qual a atividade de patrocínio é relevante para seus negócios, analisa os projetos de patrocínios enviados por empresas esportivas ou culturais, que são apresentados à empresa, uma vez que as características individuais dos projetos, por serem distintas, influenciarão nos valores e na decisão (ROCHA e CAMPOS, 2010).

Para os autores, Crescitelli el al (2005) o objetivo da estratégia de marketing de uma empresa tem maior relevância quando está ligada com as ações de patrocínio que as empresas utilizam para criação ou elevação da lembrança da marca institucional e de seus produtos junto a seus públicos-alvo. Supõe-se que a partir de um determinado volume de exposição do produto ou serviço, ocorram lembranças da marca pelos seus consumidores. 
Para Vicari e Ribeiro (2004), o valor patrimonial de uma marca está relacionado ao número de consumidores, ao grau de reconhecimento, à qualidade percebida e às fortes associações mentais e emocionais, entre outros componentes. Segundo Crescitelli et al. (2005), a lembrança das marcas só ocorre devido ao acumulo de exposição da mesma. Nos mercados competitivos, onde existem muitas marcas, a tarefa de ocupar a mente do consumidor com determinada marca, pode ser complexa pois, as ações de comunicação precisam ser contínuas, afim de formar um processo integrado de marketing. Ao expor de forma eficiente a mensagem, a fim de que os usuários ou consumidores sejam impactados, as estratégias de marketing criam um processo de repetitividade para que o público-alvo crie familiaridade com a marca, mantendo a memória viva em relação à mesma. Nesse sentido, o patrocínio atua maneira imperceptível para o consumidor, levando - o associar as marcas patrocinadoras com momentos felizes e de lazer.

Assim, o crescimento desta estratégia tem atraído o interesse crescente de pesquisadores. No contexto da interface das finanças-marketing, uma série de estudos citados por Deitz et al. (20I3), como os de Cornwell et al. (2005), Miyazaki e Morgan (200I), Clark et al. (2002) e Le- eds et al. (2007), avalia o impacto de anúncios de patrocínios a várias categorias de esporte na riqueza dos acionistas. Por isso, Meenagham et al (20I3) afirma que o patrocínio alcança uma variedade de objetivos das partes interessadas, reconhecidos na medição de desempenho, que vai além do retorno sobre o investimento no patrocínio.

Devido a isso, as empresas de capital aberto brasileiras têm patrocinado as indústrias, esportiva e criativa, visando não só obter incentivos fiscais, mas também reafirmar sua imagem como provedoras de cultura e bem-estar social, e aumentar seus mercados. Com isso fortalece a própria marca, podendo resultar na melhoria de desempenho das empresas que patrocinam (HE, 20I3).

\section{Modelo conceitual}

O modelo conceitual tem por base 0 modelo $E C D$. A estrutura da indústria na qual a empresa está inserida a leva a apresentar algumas condutas para se sobressair perante os seus concorrentes. As condutas se referem às estratégias adotadas pela empresa. $\bigcirc$ modelo pressupõe também que essas estratégias serão responsáveis pelo desempenho da empresa (KUPFER; HASENCLEVER, 2002). Assim têm-se:

$H I=A$ estrutura da indústria na qual a firma está inserida, combinadas, geram um efeito positivo sobre o desempenho da firma.

De forma complementar, a Teoria da Firma revela que as características individuais das firmas também afetam o seu desempenho. 
Segundo Barney e Hesterly (200 I), o comportamento dos agentes afeta o desempenho da firma, uma vez que adotam estratégias em relação à competitividade e organização.

Além do comportamento dos agentes, os índices financeiros relacionados à empresa podem ser fatores determinantes sobre o desempenho, como retorno sobre o ativo, endividamento e liquidez. Os índices financeiros de endividamento e liquidez representam a capacidade da firma saldar suas obrigações a longo e curto prazo (GITMAN, 2009).

$\mathrm{H} 2$ = As características específicas da firma combinadas, geram um efeito positivo sobre 0 desempenho da firma.

$\mathrm{E}$, as hipóteses de investigação desenvolvidas para este trabalho, estão relacionadas ao trabalho de Barney e Hesterly (200I),
- qual afirma estratégia adotada afeta o desempenho da mesma. Dessa forma, elaborou-se uma hipótese para cada indústria patrocinada.

H3= $O$ patrocínio à indústria esportiva influencia positivamente o desempenho econômico das empresas patrocinadoras.

$\mathrm{H} 4=\mathrm{O}$ patrocínio à indústria criativa influencia positivamente o desempenho econômico das empresas patrocinadoras.

\section{METODOLOGIA}

Esta pesquisa se caracteriza como uma pesquisa quantitativa pois esta é especialmente projetada para gerar medidas precisas e confiáveis que permitam a realização de uma análise estatística. A população do

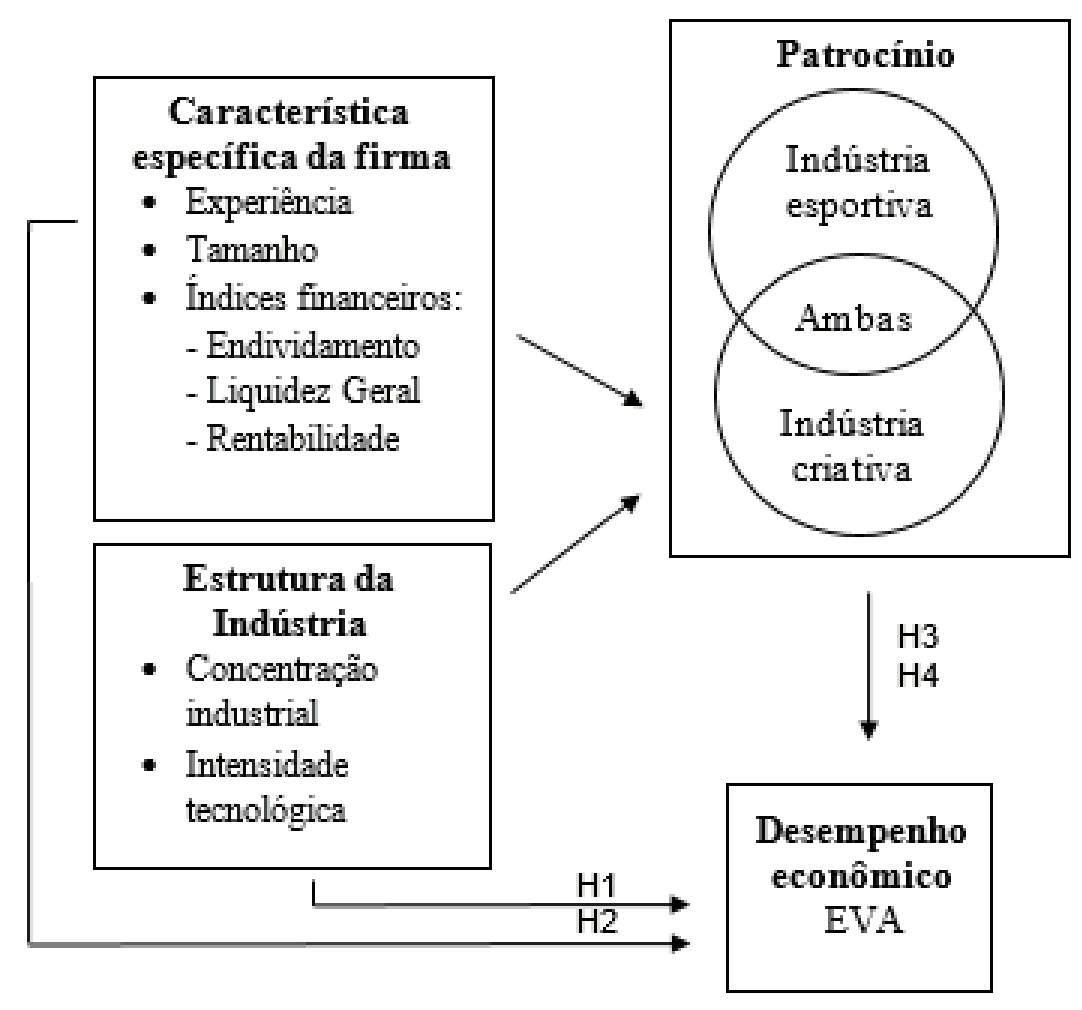

FIGURA 1 - Modelo proposto para o teste das hipóteses.

Fonte: Elaborado pelos autores 
presente estudo foi composta por empresas de capital aberto negociadas na Brasil, Bolsa, Balcão (B3)e que possuía balanço social Ibase. Conforme a base de dados do Economática, havia 398 empresas negociadas na B3. Porém, como a publicação dos balanços sociais não é obrigatória, deste total, somente 60 empresas apresentam o Balanço Social disponível no período de 2007 a 20I3, tanto no banco de dados do lbase quanto nos relatórios anuais administrativos e de sustentabilidade publicado pelas próprias empresas.

Optou-se também por excluir as empresas classificadas como instituições financeiras, por possuírem características financeiras específicas, muito diferentes daquelas das empresas de outros setores. $\mathrm{A}$ amostra então foi reduzida a 3 I empresas brasileiras de capital aberto, não financeira e que possuem Balanço Social Ibase, entre 2007 a 2013.

Buscando atender o objetivo da pesquisa, de verificar a influência do patrocínio à indústria esportiva e à indústria criativa sobre o desempenho das empresas brasileiras patrocinadoras, entre 2007 a 2013 , foi realizada uma regressão múltipla. A regressão múltipla é uma técnica de estatística multivariada classificada como técnica de dependência. Segundo Silva (20|4), a análise de regressão múltipla é um método de análise apropriado quando o problema de pesquisa envolve uma única variável dependente métrica, que é relacionada a duas ou mais variáveis independentes métricas. $O$ objetivo desta análise é prever as mudanças na variável dependente como resposta às mudanças nas variáveis independentes.

Para o presente estudo, o modelo de regressão múltipla será representado por:

$$
\begin{gathered}
\text { EVA }=\alpha+\beta_{1} \operatorname{Exp}+\beta_{2} \text { Tm }+\beta_{3} \text { End }+\beta_{4} \text { Liq }+ \\
+\epsilon \\
\beta_{5} \text { Conc }+\beta_{6} \text { Inttec }+\beta_{7} \text { Cult }+\beta_{7} \text { Espt }+\beta_{8} \text { Roa }
\end{gathered}
$$

Onde:

EVA é a medida utilizada para medir o desempenho econômico da empresa;

Exp é a experiência da empresa em anos;

Tm é o tamanho da empresa;

End representa o grau de endividamento da empresa;

Liq é o grau de liquidez da empresa;

Conc representa a concentração da indústria na qual a empresa está inserida;

Inttec é o grau de intensidade tecnológica da indústria à qual a empresa pertence;

Cult representa o valor que a empresa destina ao patrocínio da indústria criativa em reais;

Espt representa o valor que a empresa destina ao patrocínio da indústria esportiva em reais;

Roa representa índice de rentabilidade.

Para testar o modelo econométrico proposto, foi proposta a utilização de dois programas de estatística: Gnu Regression, Econometrics and Time-series Library (Gretl), versão I.9.12 e Data Analysis and Statistical Software (STATA).

Visando alcançar o objetivo proposto, o EVA foi defasado em um ano, ou seja, o valor econômico agregado foi mensurado de 2008 a 20I4. Isso porque supõe-se que a estratégia de patrocínio realizada em determinado ano influenciará o desempenho da empresa no ano seguinte.

Através dessa análise, pode-se consta- 
tar se o patrocínio as indústrias, criativa e esportiva, geram um efeito positivo sobre o desempenho das empresas que patrocinam. Além disso, qual dentre as duas indústrias geram maior valor agregado para as empresas patrocinadoras.

\section{ANÁLISE DOS RESULTADOS}

Foram analisados os Balanços Sociais Ibase de 3I empresas ao longo de sete anos, gerando 217 observações. Dentre o total de 3I empresas na amostra, todas patrocinam a indústria criativa, porém somente 25 patrocinam o esporte.

Primeiramente, foi apresentada na Tabela I, a análise descritiva das variáveis utilizadas na pesquisa, tanto as que representa as características específicas da firma quanto as que representam as características da indústria.

Para dados em painel, a normalidade dos resíduos, além do próprio teste de normalidade realizado após o resultado do modelo, pode ser também verificada por meio da curtose das variáveis, que deve ser próxima a 3. Curtose é o grau de achatamento de uma distribuição em relação a uma distribuição padrão. Nas regressões logísticas, a normalidade dos resíduos foi analisada por meio da curtose das variáveis apresentadas.

Assim, constatou que todas as variáveis, com exceção do wroe, apresentam uma distribuição normal. Como a variável wroe apresentou a curtose bem acima do valor recomendado, ou seja uma distribuição maior que a variável wroa foi excluída das análises, uma vez que ambas representam o grau de rentabilidade da empresa. Além disso, como o wroe foi utilizado no cálculo da medida de desempenho, poderia surgir uma multicolinearidade entre as variáveis EVA e wroe nas análises posteriores.

Por meio da matriz de correlação de Spearman, concluiu-se que o modelo não apresentou problemas de multicolinearidade. As variáveis independentes, com correlações significativas com a variável independente, foram endividamento, tamanho e concentração. Isso representa que essas variáveis possuem relação com a variável independente, ou seja, o patrocínio.

Esperava-se que o endividamento tivesse correlação negativa com o patrocínio, uma vez que o maior grau de endividamento poderia levar a empresa a mudar suas estratégias de patrocínio, buscando diminuir seus gastos. Essa variável, apresentou uma correlação de 0,1940, a I\% de significância, entre essas variáveis.

Já o tamanho apresentou um grau maior de correlação com patrocínios, de 0,4240 a I\% de significância. E, por fim, na concentração da indústria, que apresentou 0,1939

TABELA 1 - Estatística descritiva das variáveis utilizadas na pesquisa

\begin{tabular}{l|c|c|c|c|c|c}
\hline & Média & Mediana & Mín. & Máx. & Desvio Padrão & Curtose \\
\hline Wroe & 0,1261 & 0,1088 & $-0,3200$ & 0,7406 & 0,1719 & 6,6506 \\
\hline Wroa & 0,0524 & 0,1000 & $-0,1000$ & 0,2000 & 0,0728 & 2,7195 \\
\hline Lnwend & 4,0332 & 4,0859 & 3,1090 & 4,6249 & 0,3051 & 4,4005 \\
\hline Wliq & 0,8600 & 1,0000 & 0,0000 & 2,0000 & 0,4934 & 3,6254 \\
\hline Exp & 13,0291 & 14,0000 & 1,0000 & 27,0000 & 6,1262 & 2,2072 \\
\hline Lntam & 15,7576 & 15,5697 & 10,83441 & 20,4887 & 1,5289 & 4,3016 \\
\hline Lnconc & 1,4724 & 1,3826 & $-4,4368$ & 4,6051 & 1,8072 & 3,3500 \\
\hline Inttec & 2,7142 & 3,0000 & 1,0000 & 4,0000 & 0,7836 & 3,5133 \\
\hline
\end{tabular}


como grau de correlação com a variável patrocínio, a I\% de significância, observouse que em indústrias mais concentradas há uma maior disposição a adotar a estratégia de patrocínio.

Após a análise descritiva das variáveis, realizou-se o modelo de regressão com efeito Fixo, EF apresentado na Tabela 2.

O modelo de EF apresenta alguns problemas econométricos, uma vez que esse tipo de modelo pressupõe que os grupos possuem um intercepto comum. A partir do teste de intercepto entre grupos, obteve-se um p-valor altamente significativo a $1 \%$, o que indica que os grupos não possuem um intercepto comum.

Além disso, realizou-se o teste de normalidade dos resíduos, que também apresentou um $\mathrm{p}$-valor altamente significativo, a $1 \%$. A partir do resultado desse teste rejeitou-se a hipótese nula de que o modelo possui normalidade dos resíduos.

Também, realizou-se o teste de Wald para a heterocedasticidade no modelo. Com o P-valor próximo a 0 , indicando significância a $\mathrm{I} \%$, rejeitou a ho que pressupõe que o modelo é homocedástico. Dessa forma, esse modelo também apresentou problemas de heterocedasticidade.

$\bigcirc$ valor para Durbin-Watson apresen- tado foi de I,I6, o que poderia também indicar problemas de autocorrelação. Porém, segundo Gujarati (2006), quando se trata de uma variável dependente defasada em relação às variáveis independentes, o teste Durbin-Watson não é eficiente.

Assim, optou-se por realizar a regressão múltipla com efeitos aleatórios, antes das modificações necessárias para a correção do modelo, para que este se tornasse um modelo válido econometricamente. Os resultados do modelo de regressão múltipla com efeitos aleatórios estão apresentados na Tabela 3.

O modelo apresentado foi calculado com um intervalo de confiança de $95 \%$. O teste de Breusch-Pagan que compara o método dos mínimos quadrados agrupados com o efeito aleatório, teve o $\mathrm{p}$-valor igual a 0,000 I aproximadamente, indicando que o melhor modelo para os dados seria o efeito aleatório, a I\% de significância. $O$ mesmo resultado foi comprovado pelo teste de Hausman que não apresentou significância, com $\mathrm{p}$-valor igual a 0,30, ratificando a escolha pelo modelo com efeito aleatório.

O R-quadrado apresentou valor de 0,63, o que indica que as variáveis independentes explicam $63 \%$ das vezes a variação da

TABELA 2 - Regressão múltipla para dados em painel com efeito fixo

\begin{tabular}{|c|c|c|c|c|c|}
\hline & Coeficiente & Erro Padrão & Estatística T & \multicolumn{2}{|c|}{ P-valor } \\
\hline Const & 0,2137 & 0,0595499 & 3,5896 & 0,00042 & $* * *$ \\
\hline Wroa & $-0,1462$ & 0,0928746 & $-1,5744$ & 0,11711 & \\
\hline Lnwend & $-0,0014$ & 0,00057021 & $-2,5960$ & 0,01019 & ** \\
\hline Wliq & $-0,0360$ & 0,01835 & $-1,9663$ & 0,05077 & * \\
\hline Lntam & 0,0002 & $7,38422 \mathrm{e}-011$ & $-0,3390$ & 0,73498 & \\
\hline Exp & $-0,0004$ & 0,00132484 & $-0,3743$ & 0,70859 & \\
\hline Lnconc & $-0,0147$ & 0,0051989 & $-2,8301$ & 0,00517 & *** \\
\hline Inttec & $-0,0015$ & 0,0121759 & $-0,1265$ & 0,89949 & \\
\hline Espt & 0,0105 & 0,0030 & 3,4652 & 0,00070 & $* * *$ \\
\hline Cult & 0,0070 & 0,00354953 & 1,9865 & 0,04846 & ** \\
\hline
\end{tabular}

${ }^{*} p<0,1 ;{ }^{* *} p<0,05 ;{ }^{* \star *} p<0,01$ 
TABELA 3 - Regressão múltipla para dados em painel com efeito aleatório

\begin{tabular}{|c|c|c|c|c|c|}
\hline \multirow[b]{2}{*}{ Const } & \multirow{2}{*}{$\begin{array}{c}\text { Coeficiente } \\
0,1831 \\
\end{array}$} & \multirow{2}{*}{$\begin{array}{c}\text { Erro Padrão } \\
0,2019 \\
\end{array}$} & \multirow{2}{*}{$\begin{array}{c}\text { Estatística T } \\
0,9066\end{array}$} & \multicolumn{2}{|c|}{ P-valor } \\
\hline & & & & 0,3661 & \\
\hline Wroa & $-0,3688$ & 0,1415 & $-2,6066$ & 0,0101 & ** \\
\hline Inwend & $-0,0025$ & 0,0488 & $-0,0518$ & 0,9587 & \\
\hline Wliq & $-0,0388$ & 0,0269 & $-1,4442$ & 0,1509 & \\
\hline Intam & 0,0008 & 0,0008 & 1,0370 & 0,3015 & \\
\hline Exp & $-0,0010$ & 0,0018 & $-0,5675$ & 0,5712 & \\
\hline Inconc & $-0,0320$ & 0,0075 & $-4,4487$ & 0,0000 & $* * *$ \\
\hline Inttec & $-0,0293$ & 0,0168 & $-1,9989$ & 0,0475 & * \\
\hline Espt & 0,0149 & 0,0044 & 3,3372 & 0,0010 & $* * *$ \\
\hline Cult & 0,0083 & 0,0042 & 1,9655 & 0,0513 & ** \\
\hline
\end{tabular}

Legenda: ${ }^{*} p<0,1 ;{ }^{* *} p<0,05 ;{ }^{* *} p<0,01$

variável dependente.Ainda que em ciências sociais se considera o R-quadrado adequado acima de 0,7 , o valor relativamente baixo para o R-quadrado pode ser explicado por se tratar de dados em painel.

O valor de Durbin-Watson obtido foi de I, I5, o que poderia indicar problemas de autocorrelação. Porém, quando se trata de uma variável dependente defasada em relação às variáveis independentes, o teste Durbin -Watson não é eficiente (GUJARATI, 2006). Além disso, para modelos de efeito aleatório, pressupõe-se que os erros possuem variância aleatória, ou seja, são estocásticos e o pressuposto básico do teste de autocorrelação é que a variância dos erros seja fixa.

Realizou-se também o teste de normalidade dos resíduos, o qual apresentou p-

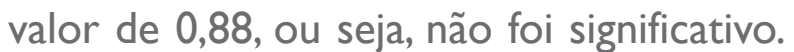
Isso indica a aceitação da hipótese nula em que 0 erro tem distribuição normal. Portanto, o erro não está ganhando estrutura que poderia enviesar a pesquisa.

O último teste realizado foi o teste de White que apresentou um $\mathrm{p}$-valor de 0,18 , aceitando a hipótese nula de ausência de heterocedasticidade. Isso indica que a variância das variáveis é igual para todas as observações. Portanto o modelo apresenta homocedasticidade.
Sobre os resultados, não se confirma a $\mathrm{HI}$, no qual a estrutura da indústria afeta positivamente o desempenho. Ambas variáveis, concentração industrial como intensidade tecnológica, possuem relação inversa com o desempenho. Ou seja, um aumento de $1 \%$ no grau de intensidade tecnológica reflete na diminuição do desempenho da empresa patrocinadora em 0,03\%, a $5 \%$ de significância. A partir do aumento do grau de intensidade tecnológica do setor, a empresa passa a investir mais em P\&D, o que desprende tempo para o desenvolvimento do produto, para - lançamento do mesmo e somente algum tempo depois essa estratégia poderá resultar em melhoria de desempenho.

O resultado para a variável de concentração não era esperado uma vez que se acreditava que quanto maior a concentração da indústria melhor seria o desempenho da empresa. Diferentemente, o resultado das análises indicou que uma maior concentração da indústria na qual as empresas estão inseridas reflete em um desempenho das empresas patrocinadoras menor. Logo, um aumento de $1 \%$ na concentração da indústria resulta na diminuição do desempenho, ou seja, na destruição de valor em $0,03 \%$, a um grau de $1 \%$ de sig- 
nificância. Por isso, a H2 que afirmava que a estrutura da indústria

Sobre as características da firma que combinadas afetam positivamente $\circ$ desempenho $(\mathrm{H} 2)$, também não pode ser confirmada. Dentre as variáveis utilizadas no modelo, apenas a variável de rentabilidade sobre $o$ ativo foi significativa e negativa, ao contrário do que se esperava. Era esperado que o aumento da rentabilidade das empresas patrocinadoras resultasse no aumento de desempenho das mesmas. Porém, o resultado do modelo também apresentou uma relação inversa dessa variável com o desempenho das empresas. Portanto, um aumento na rentabilidade sobre o ativo em $1 \%$ diminui o desempenho da empresa em $0,36 \%$, ao grau de $5 \%$ de significância. A explicação pode ser vista na defasagem do tempo, uma vez que o aumento da rentabilidade é um índice de melhoria de desempenho a curto prazo. Ou seja, um aumento na rentabilidade no tempo $t$ pode resultar também em uma melhoria de desempenho no mesmo tempo t. $E$ ainda, alto grau de rentabilidade de uma empresa não é necessariamente indicação de criação de valor como sugere Brito e Brito (2012) e Seth, Song e Pettit (2002). Muitas empresas que possuem alto nível de rentabilidade podem também estar destruindo valor.

Porém, se confirma nesse modelo ambas hipóteses de investigação ( $\mathrm{H} 3$ e $\mathrm{H} 4)$, pois tanto o patrocínio ao esporte quanto o patrocínio à cultura geram um efeito positivo sobre o desempenho das empresas. Um aumento de $1 \%$ no investimento em esportes gera um aumento de $1,4 \%$ no desempenho da empresa, o que confirma a oitava hipótese do modelo conceitual. Logo, pode-se inferir que a estratégia de patrocínio a esportes cria valor para a empresa, e que esta relação é maior que o proporcional, ou seja um investimento em esportes gera um valor econômico agregado maior ainda que o próprio investimento. Esse resultado foi obtido a um grau de I\% de significância.

Também pode-se constatar que o investimento em cultura reflete positivamente no desempenho da empresa, confirmando então a primeira e a segunda hipótese. Assim, percebeu-se que um aumento de $1 \% \mathrm{em}$ investimentos em cultura resulta em um aumento de $0,08 \%$ sobre o desempenho das empresas que patrocinam, a 10\% de significância. Da mesma forma, o investimento em cultura também cria valor para a empresa. Porém essa relação é menor que o proporcional, uma vez que o investimento em cultura será maior que o valor econômico agregado gerado por esse investimento.

A confirmação das hipóteses 3 e 4 corrobora o trabalho de Barney e Hesterly (200I) no qual afirmam que o comportamento dos agentes, ou seja, das firmas, influencia no desempenho da mesma. Neste caso, a adoção da estratégia de patrocínio à indústria esportiva e à indústria criativa afeta o desempenho das empresas positivamente

O fato de que o patrocínio a ambas indústrias resulta em uma melhoria de desempenho era esperado. Porém, o que não esperava era que o patrocínio ao esporte influenciasse mais o desempenho da empresa patrocinadora que o patrocínio à cultura, uma vez que as empresas investem mais em cultura que em esportes. Esse volume de investimentos em cultura explicase por meio da lei de incentivo à cultura, a qual favorece mais as empresas em questões de incentivos fiscais que a lei de incentivo ao esporte.

Porém, o resultado da análise apresentado pode ser explicado devido ao alcance dos 
eventos esportivos, que segundo Gastaldo (2009) são eventos mediatizados. As empresas, quando investem em esportes, destinam recursos a eventos nacionais, com grande alcance de público, o que nem sempre acontece com a cultura. Os eventos culturais com alcance nacional não são frequentes. Como exemplo, tem-se o Rock in Rio, que é um dos maiores eventos culturais nacionais mais importantes do país, e vem sendo realizado a cada dois anos.Além disso, há os filmes nacionais que alcançam altos índices de bilheteria, os quais exigem alto volume de investimentos e atraem muitos patrocinadores, porém, esses filmes são poucos.

Já eventos culturais como mostras de cinema, em Tiradentes, MG, e Gramado, RS, geralmente atingem, em sua maioria, residentes locais ou próximos, e um público consideravelmente menor quando comparado ao dos grandes eventos esportivos. Muitas vezes as empresas preferem patrocinar vários pequenos eventos, como peças de teatro, eventos musicais, exposições de artes, enfim, eventos que possuem um alcance regional, porém, representam um gasto menor para as empresas.

\section{CONLUSÃO}

A adoção da estratégia de patrocínio vem crescendo no Brasil e tem se tornado cada vez mais importante para o desempenho das firmas. As empresas buscam, por meio da cultura e do esporte, valorizar suas marcas, passando uma imagem socialmente responsável para o público. Além disso, o governo brasileiro tem desenvolvido políticas visando incentivar essas indústrias. Isso porque esse tipo de indústria envolve outras tantas indústrias, fomentando 0 consumo interno, o que pode levar ao desenvolvimento econômico do país, além do desenvolvimento social. Assim, tornou-se comum empresas investirem milhares de reais tanto em cultura como em esportes, visando ao marketing indireto à custa do desconto fiscal oferecido pelo governo.

O estudo confirma as hipóteses 3 e 4, que tanto 0 patrocínio ao esporte quanto o patrocínio à cultura geram um efeito positivo sobre o desempenho das empresas. Porém, o investimento em esporte influencia mais o desempenho das empresas que $\circ$ investimento em cultura, mesmo as empresas investindo mais nessa última indústria. Isso ainda pode ser explicado pelo incentivo fiscal, que é maior quando o patrocínio é para a cultura que quando é para o esporte. Em síntese, constatou-se que a estratégia de patrocínio, a ambas indústrias esportiva e criativa, cria valor para as empresas patrocinadoras.

As principais dificuldades no desenvolvimento do estudo se deram no processo de coleta de dados, uma vez que ainda não é comum que as empresas publiquem o seu balanço social lbase. Além disso, o site do Ibase não está atualizado, publicando alguns balanços sociais somente até 2009 , outros apenas até 2006. Dessa maneira, a coleta de dados despendeu um longo tempo, uma vez que foi necessário fazer buscas nos sítios eletrônicos de várias empresas da amostra, verificando os relatórios anuais publicados.

Uma importante limitação do estudo também se relaciona à coleta de dados, uma vez que as empresas não padronizaram o meio de publicação de seus balanços sociais, uma vez que estes são apresentados em meio ao relatório administrativo anual das mesmas, ou em meio ao relatório financeiro, ou ainda publicados à parte, em um relatório social ou de sustentabilidade. Além disso, muitas vezes as empresas 
publicam os relatórios sociais da holding e não da empresa, o que diminuiu a amostra.

Para futuros trabalhos sugere-se realizar essa análise comparativa com instituições financeiras, que são as que mais investem em cultura e esporte no Brasil. E ainda, comparar as empresas que investem em patrocínios à indústria criativa e à indústria esportiva, das empresas que não adotam a estratégia de patrocínio. 
BARNARD, A. The functions of the executive. Harvard University Presse, Cambridge, 1938.

BARNEY, Jay B.; HESTERLY, William. Economia das organizações: entendendo a relação entre as organizações e a análise econômica. HANDBOOK de estudos organizacionais. São Paulo: Atlas, v. 3, p. I3 I- |79, 2004.

BRITO, R. P.; BRITO, L. A. L. Vantagem competitiva, criação de valor e seus efeitos sobre o desempenho. Revista de Administração de Empresas, São Paulo, v. 52, n. I, p. 70-84, jan./fev. 2012.

CARNEIRO, J. M. T. Desempenho de exportação de empresas brasileiras: uma abordagem integrada. 2007.49I p.Tese (Doutorado em Administração) - Universidade Federal do Rio de Janeiro, Rio de Janeiro, 2007.

CRESCITELLI, E.; MATTAR, F. M.; SILVA, L. L. A. O efeito das ações de patrocínio sobre o top of mind um estudo exploratório do mercado brasileiro. Revista Eletrônica de Gestão de Negócios, São Paulo, v. I, n. 2, p. 34-53, jul./set. 2005.

CRUBELLATE, J. M.; PASCUCCI, L.; GRAVE, P. S. Contribuições para uma visão baseada em recursos legítimos. Revista de Administração de Empresas, São Paulo, v. 48, n. 4, p. 8-19, out./dez. 2008.

DEITZ, G. D.; EVANS JUNIOR, R. D.; HANSEN, J. D. Sponsorship and shareholder value: a re-examination and extension. Journal of Business Research, Athens, v. 66, n. 9, p. I427-I435, Sept. 2013.

GASTALDO, E. O país do futebol mediatizado: mídia e copa do mundo no Brasil. Sociologias, Porto Alegre, ano I I, n. 22, p. 352-369, 2009.

GITMAN, L. J. Princípios de ad- ministração financeira. 12. ed. São Paulo: Pearson Prentice Hall, 2010.

GUJARATI, D. Econometria básica. Rio de Janeiro: Elsevier, 2006.

HOJl, M. Administração financeira: uma abordagem prática: matemática financeira aplicada, estratégias financeiras, análise, planejamento e controle financeiro. 5. ed. São Paulo:Atlas, 2006.

HOLANDA FILHO, S. B. Estrutura industrial no Brasil: concentração e diversificação. Rio de Janeiro: IPEA/INPES, 1983.

KAYO, E. K.; KIMURA, H.; BASSO, L. F. C.; KRAUTER. Os fatores determinantes da intangibilidade. Revista de Administração Mackenzie, São Paulo, v. 7, n. 3, p. I I2-I30, 2008.

KUPFER, D.; HASENCLEVER, L. Economia industrial: fundamentos teóricos e práticas no Brasil. Rio de janeiro: Elsevier, 2002.

MEENAGHAN, T. Measuring sponsorship performance: challenge and direction. Psychology and Marketing, New York, v. 30, n. 3, p. 385-393, Mar. 2013.

PENROSE, E. A teoria do crescimento da firma. Campinas: UNICAMP, 2006. 387 p.

PEREZ, M. M.; FAMÁ, R. Ativos intangíveis e o desempenho empresarial. Revista Contabilidade \& Finanças, São Paulo, v. I7, n. 40, p. 7-24, 2006.

PETERAF, M. The cornerstones of competitive advantage: a resource -based view. Strategic Management Journal, Sussex, v. I4, n. 3 , p. I79-191, 1993.

REIS, A. C. F.; SANTOS, R. C. Patrocínio e mecenato: ferramentas de enorme potencial para as empresas. Revista de Administração de Empresas, São Paulo, v. 36, n. 2, p. 17-25, 1996.

ROCHA, P. L. A.; CAMPOS, F. S. Uma avaliação das características mais relevantes em projetos de patrocínio de eventos e sua relação com os objetivos almejados. $\mathbf{R e}$ vista Eletrônica de Administração, Rio de Janeiro, v. 16, n. I, p. 30, jan./abr. 2010.

RUGMAN, A.; VERBEKE, A. Edith Penrose's contribution to the resource based view of strategic management. Strategic Management Journal, Sussex, v. 23, n. 8, p. 769-780, 2002.

SCHERER, F. M.; ROSS, D. Industrial market structure and economic performance. $3^{\text {rd }}$ ed. Chicago: RaudMcNally, 1990.

SELZNICK, P. Leadership in administration: a sociological interpretation. New York: Haper \& Row, 1957.

SETH, A.; SONG, K. P.; PETTIT, R. Value creation and destruction in cross-border acquisitions: an empirical analysis of foreign acquisitions of U.S. Firms. Strategic Management Journal, Sussex, v. 23, p. 921 -940, 2002.

SILVA, D. Tópicos avançados de estatística na pesquisa em administração de empresas: limites e seleção de métodos e técnicas para análise. Disponível em: <http://www.ufmt.br/ufmtvirtual/aulal.doc.> Acesso em: 14 fev. 2014.

WERNERFELT, B. A resource-based view of the firm. Strategic Management Journal, Sussex, v. 5, p. I7I-I80, 1984.

YOUNG, D. S.; O BRYRNE, S. F. EVA e gestão baseada em valor: guia prático para implementação. Porto Alegre: Bookman, 2003. 